\title{
Job Stress and Work Performance of Marketing Professionals
}

\author{
Dr. Sadia Ayaz ${ }^{1}$ \\ Dr. Sabahat Alamgir ${ }^{2}$ \\ Muhammad Salar Arif Khan ${ }^{3}$
}

ABSTRACT

Marketing professionals are under a great deal of stress due to many antecedents of stress such as overload, role ambiguity, role conflict, responsibility, participation, etc. The stress badly affects the physical, cognitive and behavioural health and also effects professionalism as well as person's consistency in the environment and acceptance to change .The outcomes of stress is also seen on work performance. This study examines the relationship between job stress and work performance by using $(n=3200)$ data of marketing professionals, designated as managers and assistant managers in multinational companies working in Pakistan. The data obtained through questionnaire and analysed on percentages. The comparison of the level of stress and performance showed that out of respondents who had low stress $58.33 \%$ were performing at a high level as compared to the $70 \%$ respondents who had high stress but their performance was low. The difference between the above two percentages was $11.67 \%$ which supported the hypothesis. The results showed that job stress significantly reduce the performance of an individual. The results also suggested that organization should plan to help the employees in coming out of stress.

Keywords: : Job stress, work performance, marketing professionals

\section{INTRODUCTION}

The growing competition era like nowadays, has took organizations at a place where the fittest will survive to retain and gain the positions. In this process human capital has been put under stress. Job demands cannot be met where the excessive pressure is present, relaxation turns to exhaustion and a sense of satisfaction replaces with the feeling of stress, motivation sheds away and the workers start losing their interest in the work hence performance tends to move from high to low level. Continued and prolonged stress may result in fatigue, anxiety, tension and extreme irritability. If severe and prolonged it will result in exhaustion and may cause depression and anxiety (Seyle, 1946).

Job stress is the harmful physical and emotional response that occurs when there is a poor match between job demands and the capabilities, resources, or needs of the worker (NIOSH ,2004). Stress in the workplace reduces productivity, increases management pressures, and makes people ill in many ways, evidence of which is still increasing. Workplace stress affects the performance of the brain, including functions of work performance; memory, concentration, and learning so it effects both physical and mental health, which include increased heartbeat ,headache, lack of concentration ,poor judgements etc. Performance is also important for the individual. Accomplishing tasks and performing at a high level can be a source of satisfaction, with feelings of mastery and pride. Low performance and not achieving the goals might be experienced as dissatisfying or even as a personal failure.

Performance is defined as the outcomes and accomplishments valued by the organization or system that one works in (Hussain, Raza, Aziz, Ejaz, Haq \& Neiman, 2010). Moreover, if it is

${ }^{1}$ HEC Supervisor, Department of Housing, Home Management \& Interior Design, Govt. College of Home Economice, Gulberg,

Lahore, Pakistan, Email: drsadiafaroq@gmail.com

${ }^{2}$ Chairperson, Department of Product \& Industrial Design, University of Engineering \& Technology, Lahore, Pakistan.

${ }^{3}$ MS, Computer Engg. Deptt. UET, Lahore, Pakistan.

\begin{tabular}{llll}
\hline JISR-MSSE & Volume 15 & Number 1 & Jan-June2017
\end{tabular} 
recognized by others within the organization, is often rewarded by financial and other benefits. Performance is a major although not the only prerequisite for future career development and success in the market. Although there might be exceptions, high performers get promoted more easily within an organization and generally have better career opportunities than low performers (VanScotter, Motowidlo, \& Cross, 1996).

The study involved the marketing professionals as respondents to investigate the effect of job stress on performance; the data was collected from Pakistani organizational environment. Marketing professionals are involved at all stages of business development. In short the duties of marketing professionals are to plan "The right product, in the right place, at the right time, at the right price" (Adcock, 1983). Organizations need highly performing marketing professionals in order to meet their goals, to deliver the products and services they specialized in, and finally to achieve competitive advantage. A survey by the LinkedIn organization working for marketing professionals in Pakistan showed that currently marketing and brand management ranked the top profession so the marketing professionals are amongst the highest grossing in the country, with the emergence of multinational giants on Pakistan's economic front. They have high pay scale and a lot of chances for promotion but even then they were not fully satisfied of their jobs. The possible reason for dissatisfaction might be stress which leads to low performance so the research planned to identify the relationship of job stress and work performance of marketing professionals.

\section{Objectives of the study}

The study planned to investigate the following objectives:

- To find out the level of job stress.

- To find out the level of work performance.

- $\quad$ To find out the relationship between job stress and work performance.

\section{LITERATURE REVIEW}

Stress is an unwanted reaction people have to severe pressures or other types of demands placed upon them. A huge and multi fields literature pointed towards a lot of key factors such as work environment, management support, work load etc. in determining the stressful the work can be and its effect on employee physical and mental health (Kahn, \& Quinn, 1970). Job stress has been also viewed as dysfunctional for organizations and their members. Although stress has been variously viewed as an environmental stimulus to an individual (Kahn, \& Quinn, 1970). Stress is an individual's reaction to an environmental force that effects an individual performance (Selye, 1976). Job related stress can be mostly immobilizing because of its possible threats to family functioning and individual performance (Jagdish, 1994).

While there is a significant body of research which deals with work and family there is relatively little research e.g. Jacobson, 1987 which deals specifically with perceived job insecurity (i.e., concerns or fears about job loss) and marriage and family life e.g., Buss \& Redburn, 1983. Stress condition which happens when one realizes the pressures on them, or the requirements of a situation, are wider than their recognition that they can handle, if these requirements are huge and continue for a longer period of time without any interval, mental, physical or behaviour problems may occur. 
Stress exists in every organization either big or small the work places and organizations have become so much complex due to which it exists, work place stress has significant effects over the employees job performance, and the organizations in UK are trying to cope with this scenario, (Anderson, Coffey, \& Byerly, 2002). Eleven forces were used as an antecedents of stress by researches (Overload, Role vagueness, Role conflict, Responsibility for people, Participation, Lack of feedback, Keeping up with quick technological change, Being in an innovative role, Career growth, Organizational structure and environment, and Recent episodic events.,) Overload :excessive work or work that is outside one's capability (Bamba, 2016).

Role Ambiguity : Role insufficient information concerning powers, authority and duties to perform one's role. Role Conflict: Supervisors or subordinates place contradictory demands on the individual(David, 1998) Responsibility for people: Responsibility for people, well-being works, job security, and professional development Participation: Extent to which one has influence over decisions relevant to one's job. Lack of Feedback: Lack of information about job performance. Keeping up with rapid technological change: Keeping up with rapid changes in the information processing field. Being in an innovative role: Having to bring about change in the organization (Kahn, et al.1970). Career development: Impact of status dissimilarity, lack of job security, let down ambition (Bamba, 2016). Recent episodic events: Certain life events, such as divorce and bereavement, those are highly stressful.

Jamal (2011) studied an association between job stress and job performance between managers and blue-collar employees. Stress on job can be stated as the outcome of an individual due to the working environment from which he feels unsecured. Different relationships are projected between job stress and performance: U-shaped and curvilinear, positive linear, negative linear and no relationship between the stress and performance. A random sample of 305 blue-collar and 325 managerial workers in Canadian firm are surveyed through structured questionnaire. Variables used for this study were job stress, job performance, and organizational commitment. A negative linear relationship between job stress and job performance was found. Very limited evidence is seen for curvilinear or no association.

A mainstream group of employees articulated that their organizations did not care for its employees and sometimes employees don't like to work with their organizations indicating high levels of stress among them and majority were between the age brackets of 26-35 years. Misfit with organization, no part in decision making, were reported main causes of stress as well no control over work environment, personality traits, lack of relaxation along with ambiguous rules affect employees performance (Meneze, 2005).

Stress results in high portion of absence and loss of employment. The ratio of stress affectees in organization are increasing on alarming rate which effects both the employee performance and goal achievement. Khuwaja (2002) stated the stress as mental strain from the internal or external stimulus that refrains a person to respond towards its environment in a normal manner. These stress levels can be internal or external, from their personal lives or professional lives. Stress is a term that refers to sum of physical mental emotional strains or tensions on a person or feelings of stress which result from interactions between people and their environment that are perceived as straining or exceeding their adaptive capacities and threatening their wellbeing, in addition stress has a wide psychological and physical effect as cardiovascular, musculoskeletal systems, headache, gastrointestinal problems, sleep 
disturbance and depression. Further researched that occupational stress inadvertently consequences low organizational performance.

The importance of stress is highlighted nowadays by the employers to manage and reduce stress through practical guidelines in public sector but not in private organizations. Positive correlation has been shown by the literature between incentives and performance as both are related with satisfaction of employees, however every time the case is not same non-monetary incentives like career advancement, prestige, and public recognition can also increase performance because low morale, high turnover, and interdepartmental struggle were baselines of many cases (Mehmood, Hussain, \& Muhammad, 2010).

A survey was conducted by Kousar, Dogar, Ghazal \& Khattak ( 2006) to assess the levels of stress among five different departments of a Multinational Corporation located near Faisalabad to see the effect of stress on employee performance. Occupational stress scale (OSS) consisting of nine factors contributing to stress was used to assess stress level of workers and its effect on performance was measured by the job performance rating scale. Results showed that employees in the Human Resource, Productions, Engineering \& Refrigeration, Stores and Electrical \& Instrument Departments had moderate levels of stress due to work overload, co-workers and repetitive work. However there was significant negative correlation between workload and job performance. But there was no significant relationship between level of overall stress and job performance.

In the study by Bashir \& Ramay (2010) stated that stress was a universal experience in the life of each and every employee even executives lost due to stress and nearly $50 \%$ to $75 \%$ disease were related to stress. That study discloses the impact of stress on employees of organizations regardless of any discrimination of male and female employees, kind of organization, and department. A research was carried out by Sheraz \& Wajid (2010) to identify role of different contributing factors of job stress and to investigate level of stress on those factors among different departments of Wall's Unilever Pakistan. And also to find that how job performance is affected by job stress. Workload, co-workers and repetitive work are identified as the major factors causing stress. There was moderate level of stress with no significant difference in different departments however no effect of stress was found on job performance in the selected organization. The studies were done on stress and performance from a number of views but the present study was planned for marketing professionals, to find the relationship of stress and performance.

\section{THEORETICAL FRAME WORK}

Ambiguity can cause stress.

Role ambiguity can occur in the workplace, for instance when there are no clear guidelines, standards for performance and no clear consequences. Role ambiguity is stressful because people are uncertain about what actions and decisions to make.

\section{Proposition}

Ambiguity cause stresses when a person does not cope with the situation because the lack of clarity to perform functions especially in the workplace where rules and standards are not define. In this situation a person cannot perform up to the standard. These stresses cause performance to be poorer and poorer. 


\section{Hypothesis}

The hypothesis was developed on the basis of theoretical framework that what is the effect of stress on the performance.

More the job stress, lesser the work performance of marketing professionals.

\section{Operationalization of the variables}

The two variables were involved in the study, job stress was independent variable and work performance was dependent variable. The operational definitions were formed to determine the dimensions and elements.

\section{Operational Definition}

Job stress is the situation in which a person cannot meet his work targets and specifications to a required level because of physical, cognitive and behavioral changes in him.

\section{Dimensions}

- $\quad$ Physical changes

- Behavioural changes

- Cognitive change

\section{Elements}

Physical changes lead to the

- Aches/pains

- Heart beat

- Diarrhea/nausea

\section{Behavioural changes lead to the}

- Isolating from others

- $\quad$ Neglecting responsibilities

- Moodiness

- Short temper

- Depression/Unhappiness

\section{Cognitive changes causes}

- Memory problem

- Inability to concentrate

- $\quad$ Poor judgement

- Anxious /worrying

\section{Operational definition}

Work performance is the response to work and its accomplishment which depends on professionalism, his consistency in work and his acceptability to any kind of change at the work place.

\section{Dimensions}

- $\quad$ Professionalism

- $\quad$ Consistency and acceptance to a change 


\section{Elements}

Professionalism is dependent on the

- Time management

- $\quad$ Organization in a person life

Consistency and acceptance to a change depends on

- Control and clarity

- Innovative and initiative

- Work place and environmental adjustment

\section{RESEARCH DESIGN}

That was an explanatory study .The population was marketing professionals of multinational companies in Pakistan. Six companies were taken as target population. The proportionate sample was taken, to include the equal percentage of all the companies. Ten percent was taken from each company.

The detail is given in the table no.1:

Table .1 Target Population and Selected Number of Sample

\begin{tabular}{cccc}
\hline No. & Companies & $\begin{array}{c}\text { Total No. of Marketing } \\
\text { Professionals }\end{array}$ & No. of Respondents \\
\hline 1 & Coop Norge & 7000 & 700 \\
2 & Harrods Aviation & 4000 & 400 \\
3 & Reebok & 6000 & 600 \\
4 & Siemens & 4500 & 450 \\
5 & Schering & 5000 & 500 \\
6 & Mont Blanc & 5600 & 560 \\
\hline Total & - & 33000 & 3300 \\
\hline
\end{tabular}

Sample Consists of $\mathrm{N}=3300$ marketing professionals, The researcher selected only the persons working as managers and assistant managers.

\section{Instrument}

Questionnaire was selected due to large number of respondents. The questionnaire was used to save the time instead of taking interviews from each respondent so it was convenient as well as economical to use. Likert scale was used to evaluate a person for variables which made on five points from 1 for strongly disagree to 5 for strongly agree

Some demographical feature were also included in the questionnaire such as ranks, gender and job duration. Pilot test was conducted to check the authenticity of the instrument and then to finalize the instrument. Forty marketing professionals of a company were selected and they were not included in the actual sample. The respondents fill the questionnaire after brief instructions by the researcher. The respondents asked to clear a few questions while filling the questionnaire which were simplified for the actual data collection. There was no variation in the responses of three questions which were also changed. 


\section{Data Collection}

The administrations of the companies were contacted to gather the data. The administrations took the responsibility to fill the questionnaire from their employees instead of giving permission to the researcher to contact the respondents by herself. A lot of issues were discussed with the administrations before starting the data collection. The administrations were given instructions about who fill the questionnaire, how to use the rating scale, how to contact the researcher to solve any queries by the respondents or administrations, and how much time spend in all the process. The researcher kept the daily contact on telephone with administration to know about the process of distribution and collection of the questionnaire as well as to give answers to the queries of the respondents. The researcher also visited the companies when necessary during the process of data collection. The data was gathered within three weeks from all the companies. The detail of collected demographical features is given in table.2:

Table .2 Demographical Features

\begin{tabular}{lll}
\hline Demography & F & \% \\
\hline Ranks & 1800 & 56.25 \\
\hline Managers & 1400 & 43.75 \\
Assistant managers & 3200 & 100 \\
Total & & \\
\hline Gender & 2300 & 71.87 \\
\hline Male & 900 & 28.13 \\
Female & 3200 & 100 \\
Total & & \\
\hline Job duration (in years) & 800 & 25.00 \\
\hline Less than five & 1200 & 37.50 \\
Five to ten & 1200 & 37.50 \\
Ten to onwards & 3200 & 100 \\
Total & & \\
\hline
\end{tabular}




\section{Data Analysis}

The forty three questionnaires were not properly filled and one company has not returned the 57 questionnaires because those were misplaced and the company did not agreed again to make arrangements for filling the questionnaire so total of 100 questionnaires were separated and not used in the analysis. The obtained data was separated according to the statements coming under one element. There were thirteen negative statements so there scores were reversed before analysis Then two score indexes were formed separately for the level of stress and work performance. The indexes were used to categorize the scores of the respondents. The indexes were divided into three categories ranging from high, medium and to low level. Then intervals were calculated to divide the total score into categories. The total statements for the level of job stress were 22 so the highest score was calculated $(22 * 5=110),(5$ is the maximum possible score for a statement)out of which minimum score (22) was minus.The remaining score (88) was divided on three (3) to get interval value which was 29.3 ,to make it a round figure 0.3 was minus and the interval value was 29 . Then total scores (110) were divided in the following categories according to the interval value.

Low $<=52$

Medium 53-81

High 82-110

The same procedure was repeated for the second score index of level of work performance. The total statements for the level of work performance were 20 so the highest score was calculated $(20 * 5=100),(5$ is the maximum possible score for a statement) out of which minimum score (20) was minus. The remaining score (80) was divided on 3 to get interval value which was 26.6 , to make it a round figure 0.4 was added and the interval value was 27 .Then total scores (100) were divided in the following categories according to the interval value.

Low $<=46$

Medium 47-73

High 74-100

\section{RESULTS}

The study was aimed at the hypothesis that the higher the level of stress lowers the work performance of marketing professionals. The data was analysed on the percentages of the frequencies taken from the categories of high, medium and low. The results were shown through univariate and bivariate tables. The difference of $10 \%$ and above was considered supportive to the hypothesis. 
Table. 3 Level of Stress

\begin{tabular}{lll}
\hline Levels & F & Percent \\
\hline High & 2200 & 68.75 \\
Medium & 600 & 18.75 \\
Low & 400 & 12.50 \\
\hline Total & 3200 & 100 \\
\hline
\end{tabular}

\section{Interpretation}

Out of total respondents almost two fourths $(68.75 \%)$ were having high level of stress and respectively only $18.75 \%$ and $12.50 \%$ were at medium and low level. That concluded, the majority of the marketing professionals were having job stress.

Table.4 Level of Performance

\begin{tabular}{lll}
\hline Level & F & Percent \\
\hline High & 500 & 15.63 \\
Medium & 700 & 21.87 \\
Low & 2000 & 62.5 \\
\hline Total & 3200 & 100 \\
\hline
\end{tabular}

\section{Interpretation}

Out of total respondents only $15.63 \%$ were having high level of performance and $21.87 \%$ were at medium level but a high percentage of 62.5 were having low level of performance. That concluded, the majority of the marketing professionals were not doing their work at the required level. 
Table .5 Relationship of Job Stress and Work Performance

\begin{tabular}{|c|c|c|c|c|c|c|c|c|}
\hline \multicolumn{9}{|c|}{ Level Of Stress } \\
\hline \multirow{2}{*}{$\begin{array}{c}\text { Level of } \\
\text { performance }\end{array}$} & \multicolumn{2}{|c|}{ Low } & \multicolumn{2}{|c|}{ Medium } & \multicolumn{2}{|c|}{ High } & \multicolumn{2}{|c|}{ Total } \\
\hline & $\mathrm{F}$ & Percent & $\mathrm{F}$ & Percent & $\mathrm{F}$ & Percent & $\mathrm{F}$ & Percent \\
\hline High & 700 & 58.33 & 250 & 25.00 & 100 & 10.00 & 1050 & 32.81 \\
\hline Medium & 300 & 25.00 & 550 & 55.00 & 200 & 20.00 & 1000 & 31.25 \\
\hline Low & 200 & 16.67 & 200 & 20.00 & 700 & 70.00 & 1150 & 35.94 \\
\hline Total & 1200 & 100 & 1000 & 100 & 1000 & 100 & 3200 & 100 \\
\hline
\end{tabular}

\section{Interpretation}

Out of respondents who had low stress $58.33 \%$ were performing at a high level as compared to the $70 \%$ respondents who had high stress but their performance was low. The difference between the above two percentages was $11.67 \%$ which supported the hypothesis.

\section{DISCUSSION}

The study tested that job stress and performance were negatively related as the job stress increases the work performance decreases. The findings and the data empirically prooved the facts detailed in the literature review. A huge and multi fields literature points a lot of key factors such as work environment, management support, work load etc in determining the stressful the work can be and its effect on employee physical and mental health, (Ganster \& Loghan, 2005). The same elements were included in the study but to see the level of stress through physical and mental changes as well as changes in behaviour and the respondents were marketing professionals. In the study by Bashir (2007) stated that stress was a universal experience in the life of each and every employee even executives lost due to stress and nearly $50 \%$ to $75 \%$ disease were related to stress. That study discloses the impact of stress on employees of organizations regardless of any discrimination of male and female employees, kind of organization, and department.

The findings of the study proved that physical pains, aches, diarrhea, memory, concentration and judgement problems, moodiness, depression, isolation from others were present in the respondents. These changes and problems made the respondents stressful. The evidence is that out of total respondents almost two fourths $(68.75 \%)$ were having high level of stress and respectively only $18.75 \%$ and $12.50 \%$ were at medium and low level. The respondents also agreed to have problems in organizing themselves in their work place where they could not give consistent results and were having poor time management. The responses from the marketing professionals also showed that they have problem to give innovative ideas and have no clarity or control over work their performance was also disturbed because of their adjustments in 
work place and no acceptance to sudden changes. These all elements were included to check the performance of the individuals and the findings showed that $62.5 \%$ of the respondents were having low level of performance which indicates towards the majority of the responses. Selye also stated in 1936 that stress is an individual's reaction to an environmental force that effect an individual performance (Selye, 1946).

The majority of the respondents were having high level of stress and their performance was low at their work place.The comparison of the level of stress and performance also showed that out of respondents who had low stress $58.33 \%$ were performing at a high level as compared to the $70 \%$ respondents who had high stress but their performance was low. The difference between the above two percentages was $11.67 \%$ which supported the hypothesis. As also stated by Kahn, \& Quinn (1970) Job stress has been also viewed as dysfunctional for organizations and their members.

\section{SUMMARY}

The explanatory study was planned to find out the relationship of job stress and work performance of the marketing professionals working in the multinational companies of Pakistan. There were a number of researches which investigated the factors contributing to job stress and also to decrease the performance of the employees. The list of factors discussed ranges from work environment, management support, work load, role ambiguity, role conflict etc. to the changes in physical and mental health. Job stress also viewed as dysfunctional for organizations and their members. Job related stress also seen as immobilizing because of its possible threats to family functioning and individual performance. Work place stress has also significant effects over the employee's job performance, and the organizations in United Kingdom are trying to cope with that scenario. Stress and job performance was studied between managers and blue-collar employees. Stress studied in relation to the high portion of absence and loss of employment. A survey was also conducted in Pakistan to assess the levels of stress among five different departments of a Multinational Corporation located near Faisalabad but the findings showed that no significant relationship found between level of overall stress and job performance.

In 2007 a survey analysed about the diseases caused by stress in Pakistan. Another research was carried out in 2010 to identify role of different contributing factors of job stress and to investigate level of stress. Workload, co-workers and repetitive work were identified as the major factors causing stress. There was a moderate level of stress which had not effected the performance of the employees. The present study was planned for the marketing professionals because these persons are more exposed to the stress and strain due to work load, deadlines customer planning and thinking for the improvement for the organization. The base for the study was also the demands and ambiguity theories both contribute to the stress and the effects of stress which came in the form of changes in health.

Sample Consists on $\mathrm{N}=3300$ marketing professionals, working as managers and assistant managers.Questionnaire was used as instrument and likert scale used for assessment. Pilot test was conducted which helped in finalizing the questionnaire. The data was collected from the respondents. The obtained data was separated according to the statements coming under one element. There were thirteen negative statements so there scores were reversed before analysis. The score indexes were used to categorize the scores of the respondents. The study was aimed at the hypothesis that the higher the level of stress lower the work performance of marketing professionals. 
The findings of the study proved that physical pains, aches, diarrhea, memory, concentration and judgement problems, moodiness, depression, isolation from others were present in the respondents. These changes and problems made the respondents stressful. The evidence is that out of total respondents almost two fourths $(68.75 \%)$ were having high level of stress and respectively only $18.75 \%$ and $12.50 \%$ were at medium and low level. The respondents also agreed to have problems in organizing themselves in their work place where they could not give consistent results and were having poor time management. The responses from the marketing professionals also showed that they have problem to give innovative ideas and have no clarity or control over work their performance was also disturbed because of their adjustments in work place and no acceptance to sudden changes. These all elements were included to check the performance of the individuals and the findings showed that $62.5 \%$ of the respondents were having low level of performance which was by the majority of the responses. On the basis of the results it was seen that the whole population suffering from stress which reduce their performance in the multinational companies of Pakistan.

\section{CONCLUSION AND RECOMMENDATIONS}

On the basis of the results it was seen that the whole population suffering from stress which reduce their performance of the multinational companies in Pakistan. The dimensions were taken from the previous studies such as physical mental and behaviour changes to see the stress level as well as professionalism, consistency and acceptability to change to see the performance level. The findings showed the presence of all these elements in the respondents which lower their work performance.

Now effective management should be practiced among the marketing professionals otherwise the potential of efficient marketing professionals could be wasted causing high threat to the organizational goals and lowering overall performance. Stress management issues like counselling are unexplored options for stress management which could be employed along with monetary, non-monetary and structural reforms by the management to effectively manage the stress and retain high performance of employees. The employees should also evaluate their stress level by using the developed instrument and could help themselves in coming out from the stress by following the counselling techniques which are very easy such as watching a humorous movie, going on a walk, talking to friends etc. There are a lot of other techniques which are available on internet, they could also consult to the psychiatrist. The further research could be planned on demographical features such as to see the relationship of the age and stress on performance of the marketing professionals. 


\section{REFERENCES}

Anderson, E.S., Coffey S.B., \& Byerly T.R. (2002). Formal Organizational Initiatives and Informal Workplace Practices: Links to Work-Family Conflict and Job-Related Outcomes. Journal of Management, 28(6), 787-810.

Bamba, M. (2016). Stress Management and Job Performance in the Industries Sector of Mali. Journal of Service Science and Management. 09(03), Article ID:66432,6 10.4236/ jssm.93023

Bashir, U., Ramay, M. I. (2010) Impact of Stress on Employees Job Performance: A Study on Banking Sector of Pakistan. International Journal of Marketing Studies. 02(01), 122- 126.

David, M. (1998) Motivational and stress management. Harvard Business School Publishing, Boston, Massachusetts, USA.

Hussain, S., Raza, A., Aziz, J., Ejaz, W., Haq, I., \& Neiman, S. (2010). Workload and Performance of Employees. Interdisciplinary Journal of Contemporary Research in Business, 03(05), 256-67.

International Labour Office (ILO) and joint WHO Committee on Occupational Health. (1986). Psychosocial factors at work: Recognition and control. Occupational Safety and Health Series N0.56. December. ILO. Geneva. 81.

Jagdish, K. D. (1994) "Job Stressors and Their Effects on Physical Health, Emotional Health and Job Satisfaction in a University", Journal of Educational Administration, 32(01), 59 - 78. http://dx.doi.org/10.1108/09578239410051853

Jamal, M. (2011). Job Stress, Job Performance and Organizational Commitment in a Multinational Company: An Empirical Study in two Countries. International Journal of Business and Social Science, 02(20).

Kahn, R.L., Quinn, R.P. (1970). Role stress: A framework for analyses. In: A. McLean (Ed.), Occupational mental health. Chicago: Rand McNally.

Khattak, J. K., Khan, A. M., Haq, A., Arif, M., \& Minhas, A. A. (2011).Occupational stress and burnout in Pakistan's banking sector. African Journal of Business Management, 05(01), 810-817.

Khuwaja , A. K. (2002), Comparison of Job Satisfaction and Stress Among Male and Female Doctors in Teaching Hospitals of Karachi, Department of Community Health Sciences, The Aga Khan University.

Kousar, S., Dogar, I. A., Ghazal, S., \& Khattak, I. (2006). Occupational Stress and Job Performance. Journal of Pakistan Psychiatric Society. 03(02), 93-97.

Mehmood, B., Hussain, S., \& Muhammad, N., (2010). The relationship between stress and work performance in an Industrial Environment of Faisalabad district. Pakistan Journal of Life and Social Science, 08(01), 68-72. 
Meneze M. M, 2005, The Impact of Stress on productivity at Education Training \& Development Practices: Sector Education and Training Authority.

National Institute for Occupational Safety and Health (NIOSH), (2004). Overtime and Extended Work Shifts: Recent Findings on Illnesses, Injuries and Health Behaviours. Centers for Disease Control and Prevention, U. S. Department of Health and Human Services. April. Publication no.143, Pg.49.

Reports, Statistics Canada, Catalogue no. 82-003XIE .17, No. (4) 33-37. Retrieved from Google articals.http://www.statcan.gc.ca/pub/75-001 x/2007112/ article/10466-eng.pdf

Selye, H. (1946). The general adaptation syndrome and the diseases of adaptation. Journal of Clinical Endocrinology, 6, 117.

Selye, H. (1976). Stress of life (Rev. ed.). New York: McGraw-Hill.

Sheraz, A., \& Wajid, M., (2014). Antecedents of Job Stress and its impact on employee's Job Satisfaction and Turnover Intentions. International Journal of Learning \& Development. ISSN 2164-4063 2014, 04(02), 204-226.

Van Scotter, J. R., \& Motowidlo, S. J. (1996). Interpersonal facilitation and job dedication as separate facets of contextual performance. Journal of Applied Psychology, 81, 525-531. 